\title{
Exploring the Guiding Principle or Philosophy of Knowledge Management (Km) Implementation by the Banking Leaders at the Central Bank of
} Ghana

\section{Nashiru ZM*}

Department Of Management, International Tourism and Hospitality College, Abo Bakr Al Siddiq, Al Fath, Medina, Saudi Arabia

\begin{abstract}
This explorative enquiry focuses on the guiding principle or philosophy of the leadership of the central bank of Ghana in the implementation of knowledge management. In this article, the researcher dichotomized or dissected the philosophy of the central bank of Ghana, with reference to the participants' response and the implication to the business in the banking system of Ghana. The data on this qualitative study was based on the information gathered from the five participants who took part in the study.
\end{abstract}

Keywords: Organization; Language; Management; Research

\section{Introduction}

The philosophy of any organization is defined as the thrust in the organization's vision and mission, articulated through the leaders' interpretation of the language of the philosophy (Table 1). A philosophy makes a vision unique as it embodies a character and spirit of the organization, thus defining its orientation and goals. The vision directs the collective efforts of the staff and even some of the stakeholders of the organization.

\section{Literature Reviewed}

Knowledge management is a subject matter that first emerged approximately 25 years ago. According to Koenig and Jank [1], in its early stages, $\mathrm{KM}$ was about organizing information and knowledge holistically. In these early days of KM, Davenport et al. [2] was one of the first to propose a definition of $\mathrm{KM}$, describing it as "knowledge management being a process of capturing, distributing, and effectively using knowledge". Years after, the Gartner Group created another definition of knowledge management, which is still predominantly used by researchers and practitioners. It states that Knowledge management is a discipline that promotes an integrated approach to identifying, capturing, evaluating, retrieving, and sharing all of an enterprise's information assets. These among other things include databases, documents, policies, procedures, and previously un-captured expertise and experience in individual workers $[1,3]$.

For any organization to be functioning properly, the organization culture needs to be people or user friendly and has to be for the benefits of everyone in the organization. As noted by Cardoso et al. [4]. That knowledge-centered or knowledge friendly culture is a critical factor for any successful knowledge management (KM) practice. To gage the organizations influence through performance or its impact, individual satisfaction may have to play a role as the performance results would have indicated [5-7]. Additionally, the commitment of an organization could also be used as measurement factor in terms of employee's satisfaction [8-10].

In addition to organization change, related features that have impact on knowledge management processes are leadership and organizational structure [11]. Studies have shown that KM may also mediate change in an organization and its effectiveness, which can give credence or have serious impact on knowledge management [12]. As observed by Mueller [13], Mueller pointed out that there is a correlation that existence between corporate culture and knowledge management, in which the reverse on knowledge management can also propagate organizational change at the long run.

\section{Methodology}

The case study adopted in this research involved a qualitative case study research design using semi-structured interviews. The decision to adopt the semi-structured interviews was driven by the need to ask specific questions as well as elicit the participants' perspectives on the phenomenon of interest, which could only be achieved through more probing questions [14]. In Ghana, as noted by Kommey [15], the Banking Regulator is presently the only institution practicing knowledge management. However, to date, the Banking Regulator and its adoption of KM has not been a subject of academic research. This gap in extant knowledge has created the opportunity to explore the strategies, challenges, and implementation of KM in the Banking Regulator. The present case study involved the use of interviews from top managers-one deputy governor, two heads of department (from Finance and Research Department, respectively), one staff member from the MIS/IT unit, and one member of staff from the HR department/KM expert. Use of the exploratory design yielded a deeper understanding of the motivation and processes associated with $\mathrm{KM}$ practices [16].

\section{Philosophy and Goals}

As indicated at the introduction part of this discussion, the philosophy of any organization is defined as the thrust in the organization's vision and mission, articulated through the leaders' interpretation of the language of the philosophy. A philosophy makes a vision unique as it embodies a character and spirit of the organization,

*Corresponding author: Nashiru ZM, Department of Management, International Tourism and Hospitality College, Abo Bakr Al Siddiq, Al Fath, Medina 42312, Saudi Arabia, Tel: +966555895036; E-mail: zulkarnein.nashiru@staff.Imc.edu.sa

Recieved March 21, 2018; Accepted April 09, 2018; Published April 17, 2018

Citation: Nashiru ZM (2018) Exploring the Guiding Principle or Philosophy of Knowledge Management $(\mathrm{Km})$ Implementation by the Banking Leaders at the Central Bank of Ghana. J Entrepren Organiz Manag 7: 231. doi: 10.4172/2169 026X.1000231

Copyright: (c) 2018 Nashiru ZM. This is an open-access article distributed unde the terms of the Creative Commons Attribution License, which permits unrestricted use, distribution, and reproduction in any medium, provided the original author and source are credited. 
thus defining its orientation and goals. The vision directs the collective efforts of the staff and even some of the stakeholders of the organization (Table 1).

\section{Research Finding and Discussion}

The philosophy of the banking regulator is peculiar and contingent on the economic situation of the country. This can be inferred from the response of the DG, who noted that:

A specific objective to achieve, which primarily is about stabilizing prices, that is to control inflation but also foster a high sustainable economic growth which impacts positively the lives and welfare of all Ghanaians citizens.

While the DG regarded this information as knowledge because it underscores critical motivation for employees, it is apparent that such philosophy could be broadcast. On the other hand, how information is articulated involves brainstorming and research, to define the best way of creating a culture that enables the banking regulator to achieve its vision and mission. The DG also talked about systematizing knowledge. While this was not probed further because of the defined confines in divulging information about the internal workings of the bank, the DG recognized the importance of systemizing information in knowledge creation. He offered:

We support this [philosophy] and recognize that knowledge has to be harnessed in a very systematic fashion for it to be useful in supporting our value proposition to ensure price stability.

To this end, the organization makes use of various sources of expertise, including specialized individuals who are versed in managing this knowledge.

Having exposed the culture of the organization to some extent, the subject of knowledge was defined. According to the DG, "the organization [Banking Regulator] regards both the conceptual and functional form of knowledge and work with them as such." Broaching on both terms, the HHR described it as:

It [knowledge] is functional in the sense that, as a regulator, we would require the concept in the certain field to help us to function effectively. Practically we would need a high level of knowledge and also the concepts that would enable us to function effectively so maybe I would rate concept higher than functional. Because once you know your concept, you should be able to do your analysis based on that'. Perhaps I will allocate $65 \%$ for concept knowledge and then $35 \%$ for functional knowledge-that is subjective of course.

Following from the above comments on the philosophy of knowledge management, the goals of knowledge management were further discussed. This was important, because much of knowledge management is motivated by a competitive environment, where one company strives to become the leader in a given industry. Hence, it may seem that, for an organization such as the Banking Regulator-which is a bank to commercial banks as well as the government, and is only of such organization pursuing knowledge management-may appear to be an oversimplification of what may otherwise be a pursuit of vision. The DG's first impression on this argument was that: In Knowledge Management, you don't necessarily need to have a competitor, if you have a competitor, it may change the way you organize and disseminate information in the market sense, the market competitive environment. This includes how you time and package knowledge for external consumption to assume a competitive urge and so to that extent, it shapes the way you organize or do things.

From the Regulator's point of view, the DG stressed that managing information is very important. This awareness comes from the fact that other organizations largely depend on the information they communicate. As the DG elaborated:

The decision-making of the (other) banks to a large extent also relies on the decisions that we take at the Central Bank and those decisions have to be well communicated in a manner that will be clear to them so that they do not make ambiguous decisions or actions on their path. So, that clarity requires that we package knowledge in a seamless manner that is uniformly understood by all of them.

From the statements above, it is evident that the goal of knowledge management in itself seems to be oriented towards the aspect of communicating information to the stakeholders of the bank. Thus, it may be classified under knowledge dissemination. Nonetheless, the goals are vital to the bank because of the level of importance attached to the information it gives. In all intent, information from the organization would have to be credible, free of errors, and meant to achieve the objectives of the banks, as well as other stakeholders.

One cannot diminish the importance of this goal, noting that communication with the stakeholders would have to ensure understanding. Succinctly, the goal of knowledge management is thus defined in terms of uniform communication. To this end, the staff of the organization would have to discern and understand knowledge in unified fashion, so that they speak the same language, as the DG noted. To facilitate this process, there is internal education and an education medium that ensures that information is not distorted as it is shared with all consumers of that knowledge.

Knowledge in the Banking Regulator, like in any other organization, can be categorized into explicit and tacit knowledge. From the interview responses, it was evident that the bank was well aware of both forms of knowledge. In expounding on explicit knowledge, the DG mentioned that there is usually a conscious effort to give people information that is specific to their work. The DG elaborated on this, explaining that, when specific data has been gathered and analyzed and conclusions derived, it is shared with relevant person or group of people that can used it for a particular purpose. This form of knowledge was thus

\begin{tabular}{|l|l|}
\hline Philosophy & Features the national economic goals \\
\hline Goals & $\begin{array}{l}\text { Branched out to departmental goals; goals are underpinned by Philosophy. Goals of knowledge management are presented in } \\
\text { terms of uniform communication of knowledge at designated levels }\end{array}$ \\
\hline Culture & $\begin{array}{l}\text { Timeliness, appearance; attitude that is independent of politico-cultural and social influences; oath of secrecy; honesty; dynamism and } \\
\text { strong supervision create strong base to pursue KM }\end{array}$ \\
\hline Change & Change management (operationalizing change, promptness, etc.); resistance to change; learning \\
\hline Learning & Learning for the sake knowledge management; performance assessment; staff rotation \\
\hline $\begin{array}{l}\text { Perceived impact of knowledge } \\
\text { management }\end{array}$ & Positive impact on individual work targets, organizational goals and national economy; high incentive to succeed \\
\hline Nature of work for KM & Goal or work, motivation to work, structure of work is not definite as to whether it is autotelic, for example \\
\hline
\end{tabular}

Table 1: Philosophic and cultural language of an organization. 
explicit knowledge. The DG also mentioned specific situations when the above process can lead to tacit knowledge. He further elaborated on this, noting that:

When in a discussion of a regular real life problem relating to central banking, a player within the bank or play holder may pick up some knowledge that is relevant to their work which you the translator of knowledge may not know what specific relevance that information or use that information may mean to that listener. While the above situation may be unfortunate if the listener (Risk of getting important information to people who are not bank staff) is not in the bank, it is also a useful way for staff in the bank to stumble on important information that is beneficial to task they may be working on.

\section{Culture}

In the context of the mandate of the organization that is key to the economy of the country, the socio-cultural and economic factors-such as culture, power relations, norms, politics, and reward systems affecting the KM for the organization-were discussed with the study participants. The DG noted that the organization is a highly professional institution; hence, all players in the industry are "made aware of the fact that they are working with individuals from different socio-cultural persuasions and that their objective working together as a team is to a unified objective." In view of political influences, the DG felt that political orientations did not matter much, explaining that personnel would have to "transcend political lines, political timelines, political electoral cycles and all of those." To emphasize that such a culture projects inspiration, he revealed the cultural tenets that drive the organization:

You have people of different background and to that extent, it only speaks to issues of relationships; how you work together but in relation to knowledge itself. You share the same knowledge with someone whether, they are of different cultural background or not; it's the same information. So, it's immaterial where you come from, other than driven by the same organizational culture. We try to nurture a culturecentral banking culture-that is shared by everybody from within at the same level. So trainings, unified trainings-they are all exposed to the same opportunity of knowledge and gathering information without regard to any differentiation along socio-cultural backgrounds.

When discussing this topic, the HRES provided specific cultural tenets, as follows:

Of general importance is time consciousness. We are very particular with time-reporting and leaving time. Generally, outsiders have the notion that bankers are particular of time, so we are very conscious of that. Again, the issue about time goes to meeting deadlines. We are particular about timeliness in meeting assignments. For example, we provide data for international research institutions. So, even within our research, we have an office which is in charge of giving out dates for reports to be submitted, for writing our board reports and submission of data to these international institutions. So, our timing is such that we really observe deadlines.

\section{A second point relayed was as follows:}

We can also talk about a culture like oath of secrecy. We are supposed not to reveal any information, such as data reports and others. Sometimes authorities have to be sought from management. The banking culture regards divulging of information a very serious infraction.

The HRES also spoke about honesty:
There is also honesty. When it comes to fraud, stealing, employment processes, these are open. People 'cutting corners' [not following due procedure] to make sure somebody is employed is not done here. We also sign an oath of secrecy, which is done each year.

Noting that some of the aspects of culture are written and others are not, an example of unwritten culture borders on the banking regalia:

You cannot put on anything multi-colored. The ladies should be decently dressed without exposing certain parts of the body. These are part of the unwritten culture. Generally, with the Friday wear there is a circular on the style just to make for uniformity.

These cultural tenets form the basis upon which an attitude that enables knowledge management to take place is established. The HFD shared the following as a consequence of the astute culture:

The BoG [regulator] is quite dynamic and able to supervise the banks very well. There are 27 banks and we supervisor them at least once a year. There are also the savings and loans companies. There are discount houses, rural banks, microfinance, FOREX bureaus, which we examine regularly.

The HFD admitted to the challenges in dealing with rural banks that usually have management problems, but asserted that they are able to force compliance.

\section{The Need for Change}

Change has been said to be the only constant. The top management of the bank mentioned that the organization always saw the need for change, as the financial industry is constantly evolving. To illustrate how things have changed, the DG recalled some old practices of the bank that exemplified a hitherto fixed approach. He submitted:

The Central Bank was once doing something-during the control regime, where everything in the Central Bank was fixed-called the fixed monetary policy approach and credit provisioning. For example, if you told the Commercial Banks you can only give $20 \%$ of your credit to Agriculture, you should give $30 \%$ of your credit to Commerce and that sort of thing. That era passed. Then we moved to the situation where the Central Bank was adopting a system called Monetary Targeting.

Hence, the fixed credit regime where everything was fixed has passed. Now, the Banking Regulator focuses on inflation targeting, which is more variable. The DG explained what inflation targeting was. Not being convinced by the correlation between monetary targets and price stability, the organization shifted to inflation targeting, where targeted inflation is a more direct way of stabilizing prices. This is the current framework, as he pointed out. From the perspective of the HHR, staff also recognized the need for change. The HHR representative revealed, "You have discussions with people and people mention that there is the need to do things differently." Clearly, as the head in charge of human resources, such realization was commendable. The implementation of change did not seem to carry the same charisma for the need for change. The HHR representative submitted:

When it comes to the actual implementation of change, there is a certain level of resistance. Some would want to stick to the old way of doing things because for various reasons they may think that change would create some difficulties for them. There are other people who may not have the knowledge to fit into the situation of change. For instance, currently you know that technology is one of the ways through which organizations ensure effectiveness and efficiency. But then, looking at the age groupings, you will find that those who are 
quite old would not want change and do not have the background to cope with the technology.

\section{The HHR representative gave another reason:}

There are some who just for the sake of it would resist change because they have their own reasons for it. There are some who would be influenced by certain cultural practices and in respect of that for instance in organizational culture in it they are used to a certain way of doing things; so, when you introduce something else, they will tell you that this is not how we do it.

This comment clearly shows the various levels of resistance that the organization may have to address in order to champion change management in their learning environment. Still, the HHR representative noted that most of the staff seem to respond positively and the organization "rides on their back" to effect the change they want.

With regard to the knowledge management aspect of this and many other policies, the DG offered that for each of them, the way they organized knowledge may be different. Now, a lot of information is information technology (IT) targeted and there are a lot of things that you need to do and there are IT targeting framework, which also requires a lot of transparency in the process and gradually bringing in the real sector and, monetary sector all together to take a decision on level of interest rates that is desired and trying to influence that level of interest rate through the banking system. [This] is called the monetary policy transition mechanism.

This is clearly a mechanism of change that is contingent not only on the advent and the enhancement of IT systems but on the needs of the Ghanaian economy in the face of global economic development. This is essentially change engineered at both policy and operations levels were the latter is necessitated by the former. There is usually a need to adopt an operations framework to achieve the desired new policy direction. This may necessitate changes in staffing knowledge requirement, among other modifications and initiatives.

The process of knowledge management in the organization can be impeded by bureaucracy. According to the DG, the level of bureaucracy in the bank is lower compared to other public organizations. He noted, "in relative terms [the banking regulator is] better than other public sector entities." He added that the professional bank is more professional mainly because it is more aligned to best practices of central banking around the world. The Banking Regulator learns from the best practices of Central Banking around the world, which demands that a Central Banking worker would have to be trained to work in a certain fashion, which in itself, as he recognized, is a form of bureaucracy.

A consequence of identifying the modus for change is to operationalize change. This brings to focus the flexibility with which ideas are worked into a system. While the difficulty or ease in varying processes to accommodate change needed may be relative, the DG thought that it is "fairly easier" in their context to take decisions and implement them unless they "lose an eyeball on a particular decision." Hence, in practice, immediate implementation of a directive is pursued once a decision is taken. The immediacy with which things are done is possible because, to an extent, the processes of Central Banking are detached from public sector bureaucracy owing to the independence that the constitution attaches to it, as the DG explained. He further observed:

We don't go through a whole lot of bureaucratic procedures; we are able to move faster and not held down by normal public or civil service bureaucracy, for example, hiring new staff because we see it as necessary to implement a policy that requires new talent and new experience. We don't have to write to public services to get the establishment accepted or go to civil service-we don't do that. We just go ahead and implement and, of course, under the overseeing of the Board to decide what staffing we need.

In operationalizing change or bringing about change, it was gathered from discussions that staff would need to be ready to pursue new policies and processes that would actualize the change. The HRES, commenting on the motivation for people to want to learn and adapt to new changes within the organization, noted that the motivation for some staff comes from personal enjoyment of the process of learning, among other drivers. He also added:

For us, it is not like when you are trying to impart knowledge or skill, there is a direct reward for it. So, to me, it is just the personal fulfillment that you have been able to train somebody who later on becomes recognized and for some of us having been so lucky. If you train somebody who eventually emerges as a star or as a good performer, you will have that inner satisfaction. Of course, whoever you helped to rise to that level will also recognize you. That person sees and is always grateful. Promotion as an incentive for imparting knowledge is not clear in our system.

In effect, as it emerged from the interviews, learning and training other staff is not a focal point in the assessment for promotion.

Irrespective of the advantages discussed by some of the interviewees, the HHR noted that any resistance to change-as highlighted by the DG, when explaining how an idea is worked into the system-would depend on how the entire process is managed. He elaborated on this by sharing the following perspective:

If we are fixated on the fact that the resistance would affect the process and therefore we do not put in the necessary measures to ensure success, we fail. We have to try to encourage those in this group to come to understand the reasons for which those processes are being introduced and the benefits the organizations stand to gain, in addition to the benefits that the individuals themselves would gain.

\section{Conclusion}

Knowledge management is a discipline that promotes an integrated approach to identifying, capturing, evaluating, retrieving, and sharing all of an enterprise's information assets. These among other things include databases, documents, policies, procedures, and previously uncaptured expertise and experience in individual workers.

In Ghana, a great deal of individual knowledge is woven into the processes of many. Organizations, including the Central Bank of Ghana, known as the Banking Regulator. The limited practice of KM in the corporate environment reflects the inability of leaders to harness individual talents fully to contribute to an efficient utilization of human resources to the benefit of the organization. The regulator lived by it philosophy by making its vision unique to embodied the character and spirit of the organization, thus defining its organizational principles. If leaders in the Banking Regulator can identify and implement appropriate strategies for harnessing individual knowledge, the regulator can demonstrate to other organizational leaders the optimal use of KM to achieve organizational goals.

\section{References}

1. Koenig MED, Jank DA (2012) The (Common) Sense of KM. J Inf Knowl Manag 11: $1-9$ 
Citation: Nashiru ZM (2018) Exploring the Guiding Principle or Philosophy of Knowledge Management (Km) Implementation by the Banking Leaders at the Central Bank of Ghana. J Entrepren Organiz Manag 7: 231. doi: 10.4172/2169-026X.1000231

Page 5 of 5

2. Davenport TH, Jarvenpaa SL, Beers MC (1996) Improving knowledge work processes. Sloan Manag Rev 37: 53-65.

3. Davenport TH, Prusak L (1998) Working knowledge: How organizations manage, what they know. Harvard Business School Press.

4. Cardoso L, Meireles A, Peralta CF (2012) Knowledge management and its critical factors in social economy organizations. J Knowl Manag 16: 267-284.

5. Weiss DJ, Dawis RV, England GW, Lofquist LH (1967) Manual for the Minnesota Satisfaction Questionnaire. Minneapolis, MN: Work Adjustment Project of the University of Minnesota.

6. Lim T (2010) Relationships among organizational commitment, job satisfaction, and learning organization culture in one Korean private organization. APER 11: $311-320$

7. Bellou $\vee(2010)$ Organizational culture as a predictor of job satisfaction: The role of gender and age. Car Dev Int 15: 4-19.

8. Meyer JP, Allen NJ (1991) A three-component conceptualization of organizational commitment. Hum Res Manag Rev 1: 61-89.

9. Meyer JP, Stanley DJ, Herscovitch L, Topolnytsky L (2002) Affective, continuance and normative commitment to the organization: A meta-analysis of antecedents, correlates and consequences. J Vocat Behav 61: 20-52.

10. Meyer JP, Stanley LJ, Parfyonova NM (2012) Employee commitment in context The nature and implications of commitment profiles. J Vocat Behav 80: 1-16.

11. Magnier-Watanabe R, Benton C, Senoo D (2011) A study of knowledge management enablers across countries. Knowl Manag Res Pract 9: 17-28.

12. Zheng W, Yang B, McLean GN (2010) Linking organizational culture, structure, strategy, and organizational effectiveness: Mediating role of knowledge management. J Bus Res 63: 763-771.

13. Mueller J (2012) The interactive relationship of corporate culture and knowledge management: A review. Rev Manag Sci 6: 183-201.

14. Cooper DR, Schindler PS (2003) Business research methods (7th edn.), McGraw-Hill, pp: 798.

15. Kommey R (2013) Knowledge management as a strategic tool. Daily graphic, p: 53.

16. Al-Kasasbeh MM, AL-Faouri AH, Dasgupta S (2011) Investigating the relationship between Knowledge sharing strategies and organizational Excellency Pillars. IBIMA Publishing, p: 19. 